\title{
The evaluation of smartphone versions of the visual analogue scale and numeric rating scale as postoperative pain assessment tools: a prospective randomized trial
}

\section{Évaluation des versions pour téléphone intelligent de l'échelle visuelle analogique et de l'échelle d'évaluation numérique en tant qu'outils d'évaluation de la douleur postopératoire : une étude randomisée prospective}

\author{
Lily Y. L. Chiu, MD (1) - Terri Sun, MD • Ronald Ree, MD, FRCPC • \\ Dustin Dunsmuir, MSc • Alexander Dotto, MD • J. Mark Ansermino, MBBCH, FRCPC • \\ Cynthia Yarnold, MD, FRCPC
}

Received: 29 July 2018/Revised: 10 January 2019/Accepted: 19 January 2019/Published online: 22 February 2019

(C) Canadian Anesthesiologists' Society 2019

\begin{abstract}
Purpose The Pain assessment using a novel digital application (Panda) is a smartphone application that contains the digital versions of the visual analogue scale (VAS-100) and numeric rating scale (NRS-11). This study aimed to investigate if the Panda versions of these two pain scales are equivalent to the paper versions in adult patients. Methods This was a prospective, randomized, cross-overcontrolled trial of subjects aged 19-75 yr undergoing procedures with anticipated post-surgical pain. Each subject used both the Panda and paper versions of VAS100 or NRS-11 pain scores after emergence from anesthesia and after meeting postanesthesia care unit
\end{abstract}

L. Y. L. Chiu, MD $(\bowtie) \cdot$ T. Sun, MD

Department of Anesthesiology, Pharmacology \& Therapeutics, University of British Columbia, Vancouver, BC, Canada

e-mail: lilyqiu@alumni.ubc.ca

R. Ree, MD, FRCPC · C. Yarnold, MD, FRCPC

Department of Anesthesiology, Pharmacology \& Therapeutics,

University of British Columbia, Vancouver, BC, Canada

Department of Anesthesia, Providence Health Care, St. Paul's Hospital, Vancouver, BC, Canada

D. Dunsmuir, MSc

Department of Anesthesiology, Pharmacology \& Therapeutics, University of British Columbia, Vancouver, BC, Canada

BC Children's Hospital Research Institute, Vancouver, BC, Canada
(PACU) discharge criteria. Correlations between the two tools were analyzed, and Bland-Altman agreement was calculated. The smartphone and paper versions were considered equivalent at each time point if the differences (and their 95\% confidence interval [CI]) between them were less than 20 points for the VAS-100 and 2.1 for NRS-11.

Results The two versions of the VAS-100 correlated strongly after emergence (Pearson's $r=0.93$; $P<0.001)$ and upon meeting discharge criteria ( $r=0.94 ; \quad P<0.001)$; the mean (standard deviation [SD]) Panda score after emergence was 35 (27) compared with the paper score of 37 (26) (mean

\section{A. Dotto, MD}

Department of Anesthesiology, Pharmacology \& Therapeutics, University of British Columbia, Vancouver, BC, Canada

School of Population and Public Health, University of British Columbia, Vancouver, BC, Canada

J. M. Ansermino, MBBCH, FRCPC

Department of Anesthesiology, Pharmacology \& Therapeutics, University of British Columbia, Vancouver, BC, Canada

BC Children's Hospital Research Institute, Vancouver, BC, Canada

Department of Pediatric Anesthesia, BC Children's Hospital, Vancouver, BC, Canada 
difference, - 2; 95\% CI, - 22 to 19). The mean (SD) VAS100 Panda score upon meeting discharge criteria was 21 (20) compared with the paper score of 23 (21) (mean difference, - 2; 95\% CI, - 17 to 13). For the NRS-11, Panda again correlated strongly with the original tool scores after emergence $(r=0.93 ; P<0.001)$ and upon meeting discharge criteria $(r=0.96 ; P<0.001)$; the mean (SD) Panda and paper scores after emergence were both 4 (3) (mean difference, 0.05; 95\% CI, - 1.87 to 1.96). The mean (SD) NRS-11 Panda and paper scores upon meeting PACU discharge criteria were both 3 (2) (mean difference, - 0.08; 95\% CI, - 1.41 to 1.26).

Conclusion Following emergence from anesthesia in adult patients, the digital Panda version of the NRS-11, but not the VAS-100, is equivalent to the validated paper version. In those who are ready for discharge from the PACU, the digital Panda versions of both the VAS-100 and NRS-11 agreed adequately and can be used in place of the original paper versions.

\section{Résumé}

Objectif L'application pour téléphone intelligent Panda (Pain assessment using a novel digital application, soit 'Évaluation de la douleur à l'aide d'une application numérique innovatrice') comprend les versions numériques de l'échelle visuelle analogique (EVA-100) et de l'échelle d'évaluation numérique (EEN-11). Cette étude avait pour but de déterminer si les versions Panda de ces deux échelles de douleur étaient équivalentes à leur version imprimée quand elles étaient soumises à des patients adultes.

Méthode Notre étude comparative croisée, randomisée et prospective a porté sur des patients âgés de 19 à 75 ans subissant des interventions entraînant habituellement une douleur post-chirurgicale significative. Chaque patient a utilisé à la fois les versions Panda et imprimée des scores de douleur sur l'EVA-100 ou l'EEN-11 à deux points dans le temps, soit au réveil de l'anesthésie et après avoir rempli les critères nécessaires à l'obtention du congé de la salle de réveil. Les corrélations entre les deux outils ont été analysées, et la concordance de Bland-Altman a été calculée. Les versions pour téléphone intelligent et imprimée étaient considérées équivalentes à chaque point chronologique si les différences (et leur intervalle de confiance [IC] $95 \%$ ) entre les deux versions étaient de moins de 20 points pour l'EVA-100 et de moins de 2,1 pour l'EEN-11.

Résultats Les deux versions de l'EVA-100 ont affiché une forte corrélation après le réveil ( $r$ de Pearson=0,93; $P<0,001)$ et lorsque les patients étaient prêts à recevoir leur congé ( $r=0,94 ; P<0,001)$; le score Panda moyen (écart type [ET]) après le réveil était de 35 (27) comparativement à un score de 37 (26) pour la version imprimée (différence moyenne, -2; IC $95 \%$, -22 à 19). Le score Panda moyen (ET) pour l'EVA-100 lorsque les patients étaient prêts à recevoir le congé était de 21 (20) par rapport à un score de 23 (21) pour la version imprimée (différence moyenne, -2; IC $95 \%,-17$ à 13). En ce qui touche à l'EEN-11, la version Panda a également affiché une forte corrélation avec les scores obtenus sur les outils traditionnels au réveil $(r=0,93 ; P<0,001)$ et lorsque les critères pour le congé étaient remplis $(r=0,96$; $P<0,001) ; \quad$ les scores Panda et version imprimée moyens au réveil étaient tous deux de 4 (3) (différence moyenne, 0,05; IC 95 \%, -1,87 à 1,96). Les scores Panda et version imprimée moyens (ET) pour l'EEN-11 lorsque les patients remplissaient les critères pour le congé étaient tous deux de 3 (2) (différence moyenne, -0,08; IC $95 \%$, 1,41 à 1,26).

Conclusion Suite au réveil de l'anesthésie, chez des patients adultes, la version numérique Panda de l'EEN11, mais pas celle de l'EVA-100, est équivalente à la version imprimée validée. Chez les patients prêts à recevoir leur congé de la salle de réveil, les versions numériques Panda de l'EVA-100 et de l'EEN-11 affichaient une concordance adéquate et peuvent être utilisées à la place des versions imprimées originales.

Poorly controlled acute post-surgical pain can increase the risk of chronic post-surgical pain, psychologic distress, as well as cardiac and respiratory complications. ${ }^{1-3}$ The resultant extended hospital stays, readmissions to hospital, and management of chronic pain can place an enormous economic burden on the healthcare system. ${ }^{4}$

Developing a validated, standardized, and easily accessible pain assessment tool is the first step towards improving the management of acute postoperative pain. Pain is "an unpleasant sensory and emotional experience associated with actual or potential tissue damage, or described in terms of such damage" with multiple dimensions. $^{5}$ Self-reporting is considered the gold standard for pain assessment. The $100 \mathrm{~mm}$ visual analogue scale (VAS-100) and numeric rating scale-11 (NRS-11) are two well validated self-report scales for adults. ${ }^{6,7}$ Growing evidence suggests that smartphone applications (apps) may improve compliance with disease and medication management by motivating patients to be involved in their own care. ${ }^{8-11}$ In addition to being portable and accessible, digital pain assessments have the potential to reduce human errors that could occur during manual scoring and data recording. ${ }^{12}$

While digital versions of pain scales are available for download on smartphones, few have been validated 
Fig. 1 (Left) the Panda version of the numeric rating scale-11 (NRS-11). (Right) the Panda version of the visual analogue scale (VAS-100)

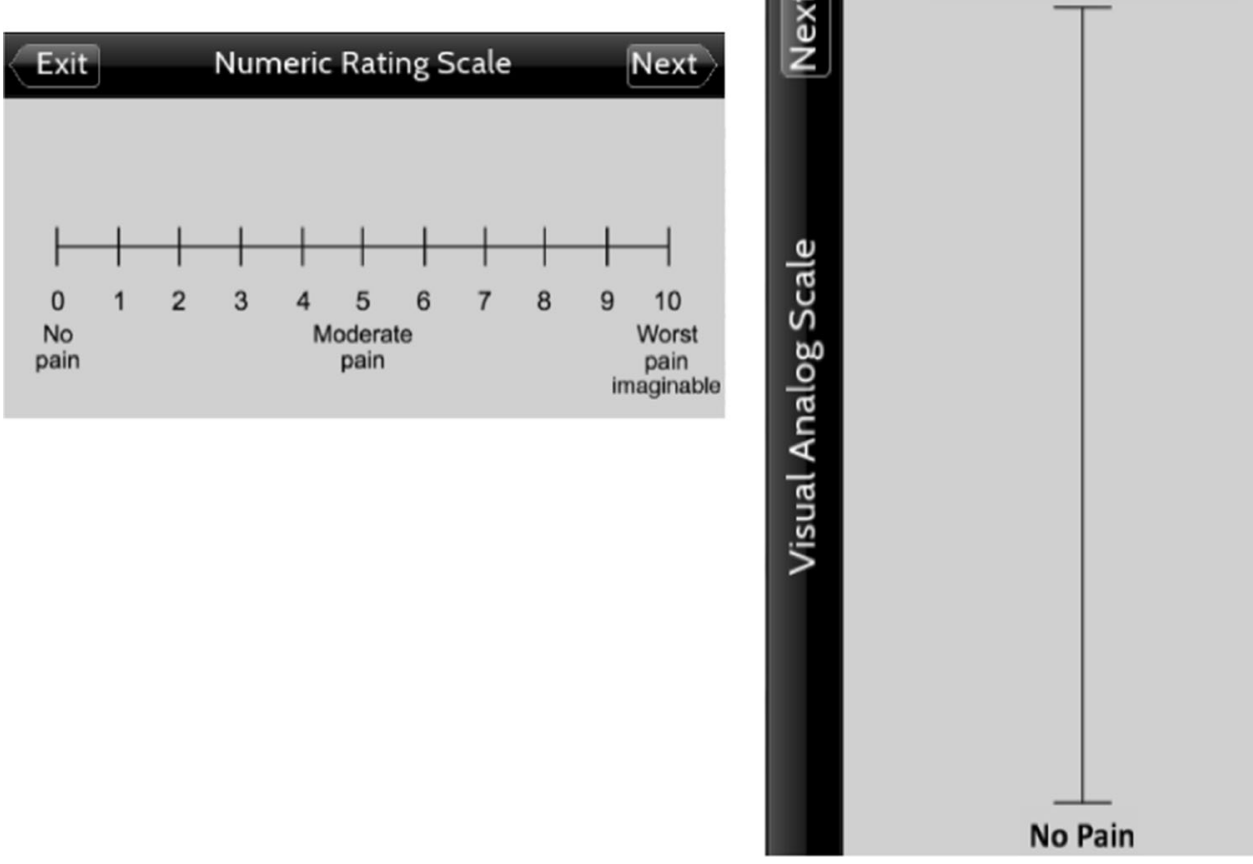

clinically in actual patients. ${ }^{13-18}$ To date, no study has established the equivalence of smartphone versions of the VAS-100 and NRS-11 to the original paper versions in the postoperative adult population. Thus, pain assessment using a novel digital application (Panda; British Columbia Children's Hospital Digital Health Innovation Lab, Vancouver, BC, Canada), a smartphone pain assessment tool originally validated in postoperative pediatric patients, was modified to include these two scales. $^{13,14}$ This study aimed to determine whether the scores obtained using the Panda versions of the VAS-100 and NRS-11 were equivalent to the original paper tools in an adult population.

\section{Methods}

\section{Trial design}

This was a prospective, randomized, cross-over-controlled, open trial. Ethics approval was obtained from the University of British Columbia-Providence Health Care Research Ethics Board (H16-01196) on 6 July, 2016. Informed written consent was obtained from all participants by a trained member of the research team.

\section{Study subjects}

Subjects were recruited in the Surgical Day Care units of St. Paul's Hospital, a tertiary academic centre, and Mount
Saint Joseph Hospital, an acute care community hospital. Inclusion criteria were: 1) aged 19-75 yr, 2) American Society of Anesthesiologists physical status I-III, 3) undergoing procedures with anticipated post-surgical pain. Patients undergoing electroconvulsive therapy, IV infusions, and diagnostic procedures were not included in the study. Other exclusion criteria included 1) undergoing eye surgery, 2) significant cognitive impairment or neurologic injury, 3) psychomotor dysfunction, 4) visual impairment, and 5) admission to the intensive care unit immediately after surgery.

Pain assessment tools

\section{Original pain scales}

The VAS-100 is a line with anchor words describing the extremes of pain from "no pain" to "worst imaginable pain". Subjects are asked to place a mark along the 100 $\mathrm{mm}$ long line to indicate the intensity of their pain. The distance in millimeters between the "no pain" anchor to this mark is then measured and denotes the pain intensity score. ${ }^{18}$ Since its introduction in 1974, it has been extensively used and studied as a pain management tool, including in the postoperative setting. ${ }^{6,19}$ The NRS-11 is a scale with the numbers $0-10$ in ascending order, with anchor words describing the extremes of pain from "no pain" to "worst pain imaginable". It requires the subjects to choose a number from $0-10$ that best represents their pain severity. ${ }^{18}$ Each scale was administered by asking 
patients to place a mark along the line using an erasable marker on laminated paper in order to reduce changes in lengths caused by repeated photocopying. The numeric score was then entered manually into the Panda application.

\section{Smartphone pain scales}

The smartphone versions of the VAS-100 and NRS-11 were reduced in size to fit onto a 3.5 inch diagonal iPod Touch screen (Apple Inc, Cupertino, CA, USA) and placed onto light blue backgrounds to enhance contrast (Fig. 1). The length of the Panda version of the VAS-100 scale is $6.7 \mathrm{~cm}$. An " $\mathrm{X}$ " marker appears where the user touches the line, marking the location along the line that indicates the severity of the pain. An integer score between 0 and 100 is calculated based on the location of the marker relative to the ends of the line. The length of the Panda version of the NRS scale is $6.3 \mathrm{~cm}$ long. The " $\mathrm{X}$ " marker appears along the line and above the number closest to where the user touches the line. The marker is placed above a number that corresponds to the subject's level of pain. The subject data were uploaded directly from the iPod Touch into REDCap (Vanderbilt University, Nashville, TN, USA) using its application programming interface, and then deleted from the device. REDCap is a secure locally hosted passwordprotected electronic data capture tool including audit trails for tracking data imports. ${ }^{20}$

\section{Scale administration}

The VAS-100 and NRS-11 were evaluated separately. The first 88 patients were allocated to the VAS-100 scale, and the remainder to the NRS-11 scale. No subject completed both scales. The first set of pain assessments at time zero $\left(\mathrm{t}_{0}\right)$ took place in the postanesthesia care unit (PACU) within $15 \mathrm{~min}$ of emergence from general anesthesia or procedural sedation, after being deemed appropriate to assess by the bedside nurse. The second set of pain assessments $\left(t_{1}\right)$ were performed when the subjects fitted the criteria for discharge from the PACU. To control for potential order effects, subjects were randomly assigned at each time point to have their pain assessed by the original paper version followed by the Panda version of the tool, or the Panda version followed by the original paper version of the tool. ${ }^{13}$ This was done using an online randomization generator. ${ }^{21}$ There was a five-minute gap between administering the paper and Panda versions. Subjects were excluded from the analysis if analgesic medication was administered during this five-minute time period. Pain medications were not administered or withheld based on pain scores obtained using Panda. The subjects' usual visual aids (eye glasses) were made available to them during the pain measurements. At the end of the study before PACU discharge, the subjects were asked whether they preferred the Panda, the original tool, or had no preference. Qualitative data on any difficulties associated with using Panda were also formally collected from subjects.

In the absence of a pre-established standardized script for administering the VAS-100, the following script was modified based on a Panda study in pediatric subjects ${ }^{13}$ : "Look at this line. The bottom of it means no pain. The top of it means the worst imaginable pain. Place an $X$ at a point on this line that shows how much pain you have right now."

In the absence of a pre-established standardized script for administering the NRS, the following script was modified based on a Panda study in pediatric subjects ${ }^{13}$ : "Look at this line with numbers. The left, where it says 0 , means no pain. The middle, where it says 5, means moderate pain. The right, where it says 10, means the worst pain imaginable. Place an $X$ at a number that shows how much pain you have right now."

Sample size and statistical analysis

The Bland-Altman method was used to calculate the agreement between the Panda and the original versions of the VAS-100 and NRS-11 at $\mathrm{t}_{0}$ and $\mathrm{t}_{1}$ with the confidence interval (CI) set at 95\%. ${ }^{13,22,23}$ Two-sided $t$ values were used to calculate the confidence interval. Sample size was calculated based on a discordance rate $\alpha$ of 0.05 and a tolerance probability $\beta$ of $80 \%$, with the assumption that there are no discordant pairs of measurements $(\mathrm{k}=0)$; the method outlined by Liao was used for the calculation, which yielded 64 subjects per group (32 per subgroup). ${ }^{24}$ The recruitment of 160 subjects was planned to accommodate for anticipated drop-out.

The primary endpoints were the agreement between the Panda and original paper versions of VAS-100 and NRS11 at $\mathrm{t}_{0}$ and $\mathrm{t}_{1}$, as determined by the minimum clinically significant differences (MCSD) of 20 points for the VAS100, and 2.1 for the NRS-11. ${ }^{19,25,26}$ The agreement between the scales was considered acceptable, and the scales were considered equivalent at that time point if the values (including the 95\% CI) were within the MCSD. In addition, Pearson's correlation coefficients were also calculated between the original and the Panda versions.

Subgroup analyses were carried out for the 19-59 yr and 60$75 \mathrm{yr}$ age groups for both scales using age cut-offs consistent with previous studies that investigated the use of pain scales in younger and elderly patient populations. ${ }^{27-29}$ In accordance with previous published studies on digital pain scales validation, the independent samples t-test was used to assess any potential effects arising from the order of administration 


\section{Enrollment}

Assessed for eligibility $(\mathrm{n}=203)$

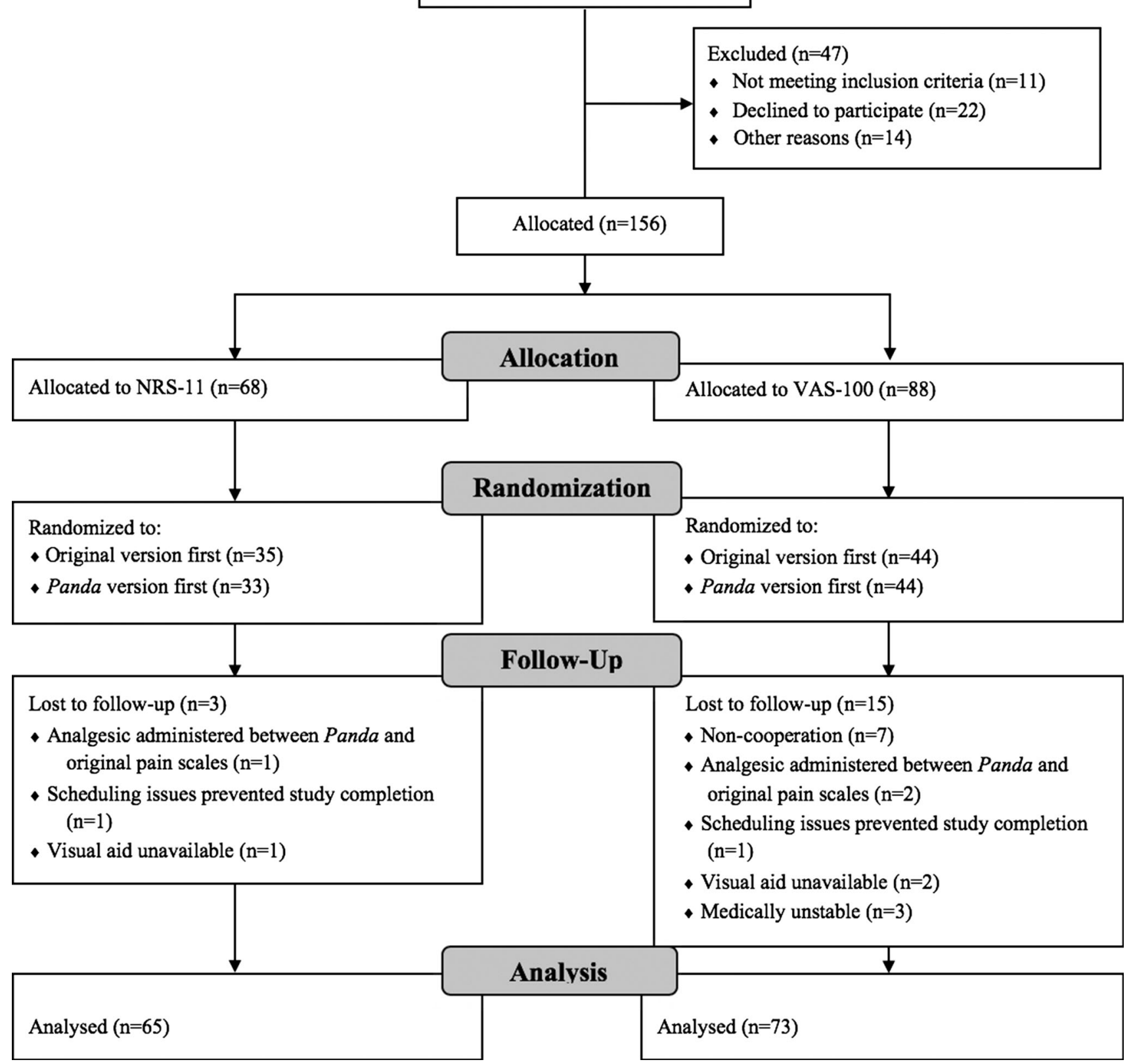

Fig. 2 Flowchart of subject enrollment, allocation, randomization, follow-up, and analysis

and differences in subgroups. ${ }^{13}$ The sign test was used to analyze subject preference for $P$ and $a$ or original versions. All $P$ values were two-sided and $P<0.05$ was considered significant. RStudio 1.1 (RStudio Inc, Boston, MA, USA) was used for statistical analysis.

\section{Results}

Study subjects

Figure 2 describes the flow of subjects from enrollment, allocation, and randomization to follow-up and analysis. Of the 156 subjects initially enrolled into the study, 18 were excluded. As a result, 138 subjects were included in the final analysis. Table 1 describes the characteristics of subjects and their surgical procedures. 
Table 1 Characteristic of the subjects and procedures

\begin{tabular}{lll}
\hline Characteristic & VAS-100 $(n=73)$ & NRS-11 $(n=65)$ \\
\hline Sex & & $26(40 \%)$ \\
Male & $19(26 \%)$ & $39(60 \%)$ \\
Female & $54(74 \%)$ & $53(13)$ \\
Age $(y r)$ & $55(14)$ & $25(38 \%)$ \\
Type of procedure & & $2(3.1 \%)$ \\
General surgery & $11(15 \%)$ & $5(7.7 \%)$ \\
Orthopedic surgery & $8(11 \%)$ & $10(15 \%)$ \\
Plastic surgery & $2(2.7 \%)$ & $16(25 \%)$ \\
Gynecologic surgery & $29(40 \%)$ & $7(11 \%)$ \\
Otolaryngology surgery & $16(22 \%)$ & $0(0 \%)$ \\
Urologic surgery & $6(8.2 \%)$ & \\
Vascular surgery & $1(1.4 \%)$ & $59(91 \%)$ \\
Type of anesthesia & & $3(4.6 \%)$ \\
General & $70(96 \%)$ & $3(4.6 \%)$ \\
Combined general and regional anesthesia & $1(1.4 \%)$ & $107(64)$ \\
Combined sedation and local anesthetic & $2(2.7 \%)$ & $119(64)$ \\
Duration of anesthesia in minutes & & \\
\hline Data & &
\end{tabular}

Data are $(\%)$ or mean (standard deviation) as indicated. NRS = numeric rating scale; VAS = visual analogue scale

Visual analogue scale-100 evaluation

Seventy-three subjects were included in the final analysis for the VAS-100 evaluation. Of these, 55 (75\%) subjects received analgesics in the postoperative period, with 39 $(53 \%)$ receiving intravenous opioids and 36 (49\%) receiving oral opioids. Forty-one (56\%) subjects were randomized to using the Panda tool first, and 32 (44\%) subjects were randomized to using the original tool first. The mean (SD) time from the anesthetic end time, as indicated by the operating room records, to the first pain assessment at $t_{0}$ was 15 (12) min. The mean (SD) time between the $t_{0}$ and $t_{1}$ was 102 (72) min. The range of pain scores was $0-95$ for both versions (Fig. 3).

On awakening in the PACU, the two versions of VAS100 correlated strongly $(\mathrm{r}=0.93 ; P<0.001)$. The mean (SD) Panda score was 35 (27) compared with the mean (SD) paper score of 37 (26) (mean difference, - 2; 95\% CI, -22 to 19). Upon meeting PACU discharge criteria, the two versions again correlated strongly $(\mathrm{r}=0.94$, $P<0.001$ ). The mean (SD) Panda score was 21 (20) compared with the mean (SD) paper score of 23 (21) (mean difference, $-2 ; 95 \%$ CI, -17 to 13) (Table 2). The 95\% CI was outside the pre-determined MCSD of $20 \mathrm{~mm}$ at $\mathrm{t}_{0}$ and within the MCSD at $t_{1}$.

Between the age 19-59 yr and 60-75 yr subgroups, the mean differences in pain scores obtained using the Panda and original scales were not significantly different at $t_{0}$ $(-2 v s-1$, respectively; difference $-2 ; 95 \% \mathrm{CI},-7$ to
3; $P=0.52)$ and $\mathrm{t}_{1}(-3 v s-2$, respectively; difference $-1 ; 95 \% \mathrm{CI},-4$ to $2 ; P=0.56)$. The order of the scale administration did not have any significant effects according to the independent samples t-test. Comparing the "original first" and "Panda first" groups, the mean differences between the two versions of VAS-100 were not significantly different at $\mathrm{t}_{0},(-3$ and 0 , respectively; difference $-3 ; 95 \% \mathrm{CI},-8$ to $2 ; P=0.18)$, and $\mathrm{t}_{1}(-3$ and -1 , respectively; difference $-2 ; 95 \% \mathrm{CI},-5$ to 2 , $P=0.33$ ). Calculated power was over $90 \%$ for both age and order of administration subgroup analyses.

Of the 34 subjects who expressed preference for one type of tool, $27(79 \%)$ preferred Panda $(P<0.001)$. Six out of 73 subjects reported difficulties making the " $X$ " marker appear on the line by pressing precisely on the line and/or moving the " $\mathrm{X}$ " to the precise position that indicated the intensity of their pain. One subject found the scale on the app to be small. Nevertheless, all subjects were able to complete the scales, and there were no instances of failure to collect pain scores from any subject.

Numeric rating scale-11 evaluation

Sixty-five subjects were included in the analysis for the NRS-11 evaluation. Fifty-three subjects $(82 \%)$ received analgesics in the postoperative period, with $34(52 \%)$ receiving intravenous opioids, and $36(55 \%)$ receiving oral opioids. Thirty-one subjects (48\%) were randomized to using the Panda tool first, and 34 (52\%) subjects were 
Bland-Altman Plot for VAS scores at $t_{0}$

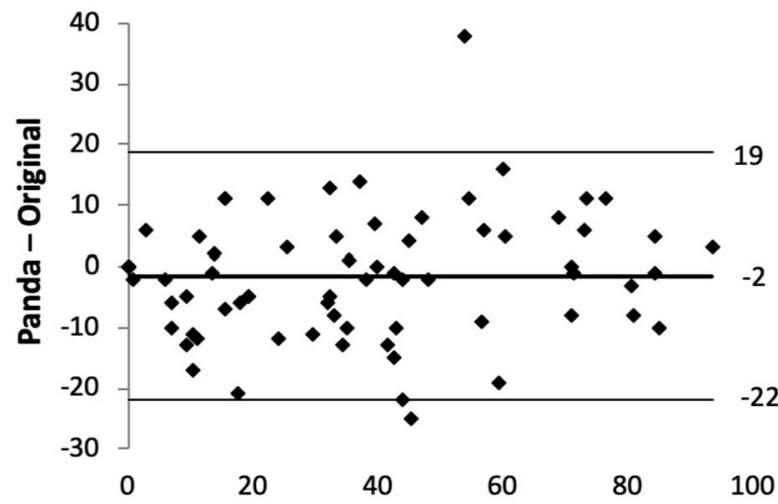

(Original + Panda) / 2

Bland-Altman Plot for NRS scores at $t_{0}$

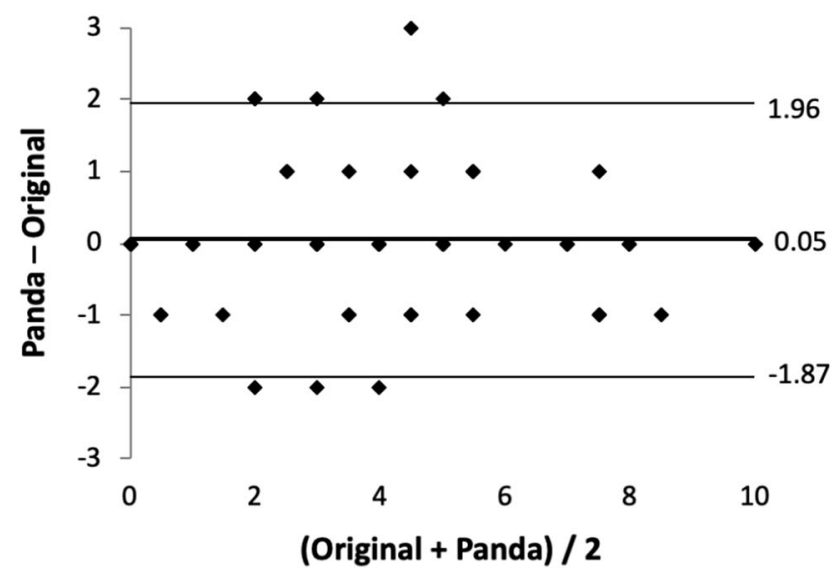

Fig. 3 Bland-Altman agreement plots between original and Panda versions of the visual analogue scale (VAS-100) at $t_{0}$ (top left) and $\mathrm{t}_{1}$ (top right) and the numeric rating scale (NRS-11) at $\mathrm{t}_{0}$ (bottom left)

randomized to using the original paper tool first. The mean (SD) time from the anesthetic end time, as indicated by the operating room records, to the first pain assessment at $t_{0}$ was 19 (19) min. The mean (SD) time between $t_{0}$ and $t_{1}$ was 63 (40) min. Pain severities from 0-10 were sampled for both versions.

On awakening in PACU, the two versions of NRS-11 correlated strongly $(\mathrm{r}=0.93 ; P<0.001)$. The mean (SD) $P a n d a$ and paper scores were both 4 (3) (mean difference, $0.05 ; 95 \% \mathrm{CI},-1.87$ to 1.96 ). Upon meeting PACU discharge criteria, the two versions again correlated strongly $(\mathrm{r}=0.96, P<0.001)$. The mean (SD) Panda and paper scores were both 3 (2) (mean difference, -0.08 ; 95\% CI, -1.41 to 1.26 ) (Table 3). The $95 \%$ CIs were within the pre-determined MSCD of 2.1 at both $\mathrm{t}_{0}$ and $\mathrm{t}_{1}$.

Between the age 19-59 yr and 60-75 yr subgroups, the mean differences in pain scores obtained using the Panda and original NRS scales were not significantly different at
Bland-Altman Plot for VAS scores at $t_{1}$

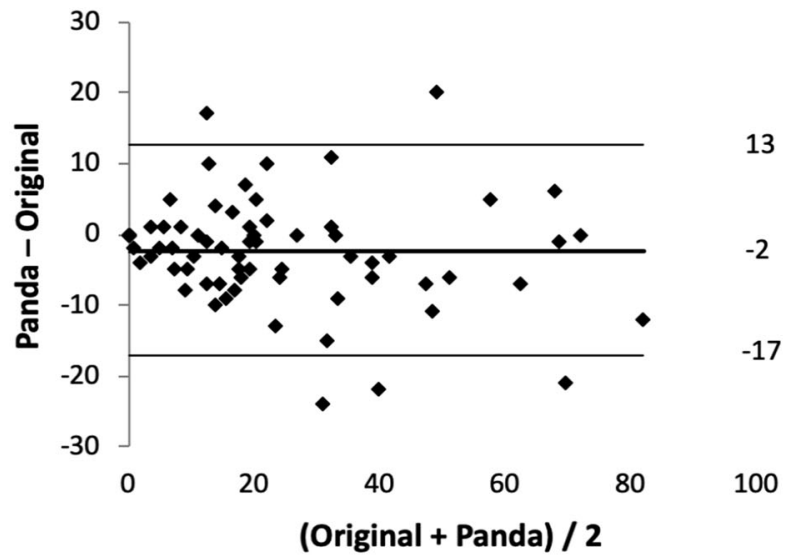

Bland-Altman Plot for NRS scores at $t_{1}$

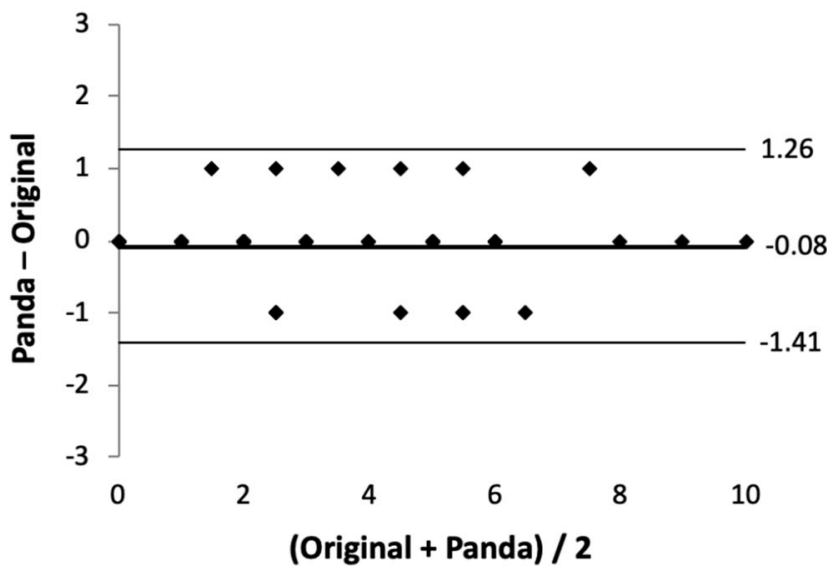

and $t_{1}$ (bottom right). The bold horizontal lines indicate the BlandAltman mean difference; the light horizontal lines indicate the $95 \%$ confidence interval

$\mathrm{t}_{0}(0.18 v s-0.16$ respectively; difference $0.34 ; 95 \% \mathrm{CI}$, -0.15 to $0.82 ; P=0.17)$ and $\mathrm{t}_{1}(-0.13$ vs 0 , respectively; difference $-0.13 ; 95 \% \mathrm{CI},-0.44$ to $0.19 ; P=0.43$ ). The order of the scale administration did not have any significant effects according to the independent samples t-test. Comparing the "original first" and "Panda first" groups, the mean differences between the two versions of NRS-11 were not significantly different at $t_{0}(0.21$ and -0.13 , respectively; difference $0.34 ; 95 \% \mathrm{CI},-0.14$ to $0.81 ; P=0.16)$, and $\mathrm{t}_{1}(0.18$ and 0.03 , respectively; difference $0.15 ; 95 \% \mathrm{CI},-0.11$ to $0.53 ; P=0.20$ ). Calculated power was over $90 \%$ for both age and order of administrations subgroup analyses.

Of the 30 subjects who expressed preference for one type of tool, $27(90 \%)$ preferred Panda $(P<0.001)$. Four out of 65 subjects found it difficult to place the " $\mathrm{X}$ " marker at the number that indicated their pain. Nevertheless, all subjects were able to 
Table 2 Correlations and Bland-Altman agreement of Panda with original visual analogue scale (VAS-100)

\begin{tabular}{|c|c|c|c|c|c|c|c|}
\hline \multirow[t]{2}{*}{ Age (yr) } & \multirow[b]{2}{*}{ Tool } & \multicolumn{2}{|c|}{ Age $19-75(n=73)$} & \multicolumn{2}{|c|}{ Age $19-59(n=41)$} & \multicolumn{2}{|c|}{ Age $60-75(n=32)$} \\
\hline & & Panda & Original & Panda & Original & Panda & Original \\
\hline \multirow[t]{4}{*}{$\mathbf{t}_{\mathbf{0}}$} & Mean (SD) & $35(27)$ & $37(26)$ & $39(27)$ & $43(26)$ & $31(27)$ & $35(25)$ \\
\hline & VAS score & & & & & & \\
\hline & Pearson's $\mathrm{r}$ & \multicolumn{2}{|c|}{$0.93(P<0.001)$} & \multicolumn{2}{|c|}{$0.93(P<0.001)$} & \multicolumn{2}{|c|}{$0.92(P<0.001)$} \\
\hline & $\begin{array}{l}\text { Bland-Altman } \\
\text { mean difference }(95 \% \mathrm{Cl})\end{array}$ & \multicolumn{2}{|c|}{$-2(-22$ to 19$)$} & \multicolumn{2}{|c|}{$-2(-22$ to 18$)$} & \multicolumn{2}{|c|}{$-1(-22$ to 20$)$} \\
\hline \multirow[t]{4}{*}{$\mathbf{t}_{1}$} & Mean (SD) & $21(20)$ & $23(21)$ & $23(19)$ & $25(21)$ & $20(21)$ & $22(22)$ \\
\hline & VAS score & & & & & & \\
\hline & Pearson's r & \multicolumn{2}{|c|}{$0.94(P<0.001)$} & \multicolumn{2}{|c|}{$0.93(P<0.001)$} & \multicolumn{2}{|c|}{$0.95(P<0.001)$} \\
\hline & $\begin{array}{l}\text { Bland-Altman } \\
\text { mean difference }(95 \% \mathrm{CI})\end{array}$ & \multicolumn{2}{|c|}{$-2(-17$ to 13$)$} & \multicolumn{2}{|c|}{$-3(-18$ to 13$)$} & \multicolumn{2}{|c|}{$-2(-15$ to 12$)$} \\
\hline
\end{tabular}

$\mathrm{CI}=$ confidence interval; $\mathrm{SD}=$ standard deviation; $\mathrm{VAS}=$ visual analogue scale

Table 3 Correlations and Bland-Altman agreement of Panda with original numeric rating scale (NRS-11)

\begin{tabular}{|c|c|c|c|c|c|c|c|}
\hline \multirow[t]{2}{*}{ Age (yr) } & \multirow[b]{2}{*}{ Tool } & \multicolumn{2}{|c|}{ Age $19-75(n=65)$} & \multicolumn{2}{|c|}{ Age $19-59(n=40)$} & \multicolumn{2}{|c|}{ Age $60-75(n=25)$} \\
\hline & & Panda & Original & Panda & Original & Panda & Original \\
\hline \multirow[t]{4}{*}{$\mathbf{t}_{\mathbf{0}}$} & Mean (SD) & $4(3)$ & $4(3)$ & $5(3)$ & $5(3)$ & $3(2)$ & $4(2)$ \\
\hline & NRS scores & & & & & & \\
\hline & Pearson's $\mathrm{r}$ & \multicolumn{2}{|c|}{$0.93(P<0.001)$} & \multicolumn{2}{|c|}{$0.94(P<0.001)$} & \multicolumn{2}{|c|}{$0.92(P<0.001)$} \\
\hline & $\begin{array}{l}\text { Bland-Altman } \\
\text { mean difference }(95 \% \mathrm{CI})\end{array}$ & \multicolumn{2}{|c|}{$0.05(-1.87$ to 1.96$)$} & \multicolumn{2}{|c|}{0.18 ( -1.74 to 2.09$)$} & \multicolumn{2}{|c|}{$-0.16(-2.05$ to 1.73$)$} \\
\hline \multirow[t]{3}{*}{$\mathbf{t}_{\mathbf{1}}$} & Mean (SD) NRS scores & $3(2)$ & $3(2)$ & $4(3)$ & $4(2)$ & $3(2)$ & $3(2)$ \\
\hline & Pearson's $r$ & \multicolumn{2}{|c|}{$0.96(P<0.001)$} & \multicolumn{2}{|c|}{$0.95(P<0.001)$} & \multicolumn{2}{|c|}{$0.97(P<0.001)$} \\
\hline & $\begin{array}{l}\text { Bland-Altman } \\
\text { mean difference }(95 \% \mathrm{CI})\end{array}$ & \multicolumn{2}{|c|}{$-0.08(-1.41$ to 1.26$)$} & \multicolumn{2}{|c|}{$-0.13(-1.64$ to 1.39$)$} & \multicolumn{2}{|c|}{$0(-1$ to 1$)$} \\
\hline
\end{tabular}

$\mathrm{CI}=$ confidence interval; $\mathrm{NRS}=$ numeric rating scale; $\mathrm{SD}=$ standard deviation

complete the scales, and there were no instances of failure to collect pain scores from any subjects.

\section{Discussion}

In this study, we aimed to determine if the smartphone versions of the VAS and NRS could be used in lieu of the original validated paper versions. Shortly after subjects emerged from anesthesia, the Panda and original paper versions of the VAS did not agree adequately within the pre-specified MCSD of $20 \mathrm{~mm}$ (as the 95\% CI overlapped $20 \mathrm{~mm}$ ). The Panda and original paper versions of the NRS agreed adequately within the minimal clinical significance of 2.1. When the subjects were ready for discharge from the PACU, the $95 \%$ limits of agreement between the Panda and original versions were within the pre-determined boundaries for both scales.

In designing the Panda application, we chose two wellknown pain assessment scales that drew upon different cognitive tasks. The VAS-100 is a graphic rating scale that requires abstract reasoning to translate the subjective experience of pain onto a length of line. ${ }^{28}$ While this type of scale is considered more sensitive, some argue that it may be more difficult to understand for subjects at risk of cognitive difficulties, such as older individuals and individuals on high opioid doses. ${ }^{18}$ In the immediate postoperative period, the impact of impaired higher cognition on the VAS could be further exacerbated by decreased fine motor skills required to manipulate the digital pain scales on a small smartphone screen. This may explain why the Panda version of VAS agreed poorly with the original paper version in patients who first emerged 
from general anesthesia or sedation. According to the agebased subgroup analysis, the age 60-75 yr group did not report any significant difficulties with the application, and there were no significant differences in the agreement with paper scales compared with the age 19-59 yr subgroup. Thus, increased age alone does not present a significant barrier to the use of smartphone versions of the VAS.

The NRS-11, which relies on numerical cues, is less sensitive, but is often considered to be easier to administer and more reliable. ${ }^{18}$ Although the sample size of the age 60-75 yr subgroup for NRS was smaller than initially desired (25 vs 32 as planned), NRS is historically less impacted by age. Moreover, the power for the subgroup ttest analysis was over $90 \%$, and the sample size for the overall age 19-75 $\mathrm{yr}$ analysis was large enough to determine equivalence.

\section{Limitations}

There were several limitations to our study. For the NRS, a full range of pain scores from 0-10 were sampled for both the Panda and original versions. However, for the VAS, scores above 95 were not sampled. This means further evaluation of the Panda version of this scale in this range may be necessary. In addition, the pain assessments began after the subjects were awake and deemed appropriate for assessment by the bedside nurse. The evaluation of the bedside nurses could be subjective and variable. The potential difference in the level of wakefulness of the subjects is a limitation that can be mitigated by recording the scores of validated sedation scales.

In regards to the pain scales, although both have been extensively studied and used for decades, there was no consensus on the specific appearances and anchor descriptors. $^{7}$ For our study, the vertical format as well as the descriptors "no pain" and "worst imaginable pain" were chosen for the VAS-100 because they were studied specifically in the immediate postoperative setting. ${ }^{19}$ For the NRS-11, the anchors "no pain" and "worst pain imaginable" were chosen because they were the most commonly used in clinical studies. ${ }^{7}$ There is also considerable disagreement between the minimally clinically significant differences for both scales. ${ }^{19,25,26,30-32}$ The MCSD for VAS and NRS in this study were chosen based on their prior use in studies on acute pain in the immediate postoperative period. ${ }^{19,25,26}$ No previous study has provided any scripts for the administration of these scales. ${ }^{7}$ The script used in this study was modified from the one used in the pediatric Panda study. ${ }^{13}$ It was readily understood, with no subject failing to provide a score from the study because they could not comprehend the instructions.

For smartphone applications in general, the visual, cognitive, and fine motor skills demanded by the small screen could present a challenge for subjects with impairments in these areas. The cost of smartphones can also be prohibitive, limiting their use in patients with low socioeconomic status.

Nevertheless, there is significant potential for the application of validated mobile pain assessment tools. Currently, the management of postoperative pain after patients leave hospital can be suboptimal, with more patients reporting pain after discharge than before. ${ }^{4}$ Smartphone ownership is at $73 \%$ in Canada, making them an increasingly accessible platform for pain management. ${ }^{33}$ While the Panda version of the VAS may not be appropriate for use in patients who have just emerged from anesthesia, it was equivalent to and can be used in place of the original version when patients are ready to be discharged from the PACU. For NRS, on the other hand, the Panda version was equivalent to the original version, both in patients who have just awakened after anesthesia and those who are ready to be discharged from PACU. These findings, therefore, have exciting implications for the further development of remote pain assessment and management applications that incorporate smartphone versions of the VAS and NRS.

Acknowledgements The authors would like to thank the nurses in the Surgical Day Care and Post Anesthetic Care Units at St. Paul's and Mount St. Joseph Hospital, as well as Mr. Nicholas West for his contributions to editing the manuscript.

Conflicts of interest None declared.

Editorial responsibility This submission was handled by Dr. Hilary P. Grocott, Editor-in-Chief, Canadian Journal of Anesthesia.

Author contributions Lily Y.L. Chiu contributed to all aspects of this study, including protocol design, data acquisition, data analysis, and manuscript drafting. Terri Sun contributed to the protocol design, data interpretation, and editing of the manuscript. Dustin Dunsmuir contributed to design of the smartphone application, the design of the study protocol, and editing of the manuscript. Alexander Dotto contributed to the analysis of data and editing of the manuscript. Ronald Ree, Mark Ansermino, and Cynthia Yarnold contributed to the conception of the study design and editing of the manuscript.

\section{References}

1. Breivik H. Postoperative pain management: why is it difficult to show that it improves outcome? Eur J Anaesthesiol 1998; 15: 748-51.

2. Shipton EA. The transition from acute to chronic post surgical pain. Anaesth Intensive Care 2011; 39: 824-36.

3. Dworkin RH, McDermottMP, Raja SN. Preventing chronic postsurgical pain: how much of a difference makes a difference? Anesthesiology 2010; 112: 516-8.

4. Apfelbaum JL, Chen C, Mehta SS, Gan TJ. Postoperative pain experience: results from a national survey suggest postoperative pain continues to be undermanaged. Anesth Analg 2003; 97: 534-40. 
5. International Association for the Study of Pain. IASP Taxonomy 2014. Available from URL: https://www.iasp-pain.org/Education/ Content.aspx? ItemNumber=1698 (accessed January 2019).

6. Huskisson EC. Measurement of pain. Lancet 1974; 2: 1127-31.

7. Hjermstad MJ, Fayers PM, Haugen DF, et al. Studies comparing numerical rating scales, verbal rating scales, and visual analogue scales for assessment of pain intensity in adults: a systematic literature review. J Pain Symptom Manage 2011; 41: 1073-93.

8. McClellan CB, Schatz JC, Puffer E, Sanchez CE, Stancil MT, Roberts $C W$. Use of handheld wireless technology for a homebased sickle cell pain management protocol. J Pediatr Psychol 2009; 34: 564-73.

9. Lim J, Cloete G, Dunsmuir DT, et al. Usability and feasibility of PIERS on the move: an mHealth app for pre-eclampsia triage. JMIR Mhealth Uhealth 2015; 3: e37.

10. Brown NJ, Kimble RM, Rodger S, Ware RS, Cuttle L. Play and heal: randomized controlled trial of Ditto ${ }^{\mathrm{TM}}$ intervention efficacy on improving re-epithelialization in pediatric burns. Burns 2014; 40: 204-13.

11. Kirwan M, Vandelanotte C, Fenning A, Duncan MJ. Diabetes self-management smartphone application for adults with type 1 diabetes: randomized controlled trial. J Med Internet Res 2013; 15: e235.

12. Sindhu B, Shechtman $O$, Tuckey L. Validity, reliability, and responsiveness of a digital version of the visual analog scale. $\mathrm{J}$ Hand Ther 2011; 24: 356-63.

13. Sun T, West $N$, Ansermino JM, et al. A smartphone version of the faces pain scale-revised and the color analog scale for postoperative pain assessment in children. Pediatr Anesth 2015; 25: 1264-73.

14. Wood $C$, von Baeyer $C$, Falinower $S$, Moyse D, Annequin D, Legout $V$. Electronic and paper versions of a faces pain intensity scale: concordance and preference in hospitalized children. BMC Pediatr 2011; 11: 87.

15. Cravero JP, Fanciullo GJ, McHugo GJ, Baird JC. The validity of the computer face scale for measuring pediatric pain and mood. Pediatr Anesth 2013; 23: 156-61.

16. Bird ML, Callisaya ML, Cannell J, Gibbons T, Smith ST, Ahuja $K D$. Accuracy, validity, and reliability of an electronic visual analog scale for pain on a touch screen tablet in healthy older adults: a clinical trial. Interact J Med Res 2016; 5: e3.

17. Castarlenas E, Sanchez-Rodriguez, E, de la Vega R, Roset $R$, Miro $J$. Agreement between verbal and electronic versions of the numerical rating scale (NRS-11) when used to assess pain intensity in adolescents. Clin J Pain 2015; 31: 229-34.

18. Jensen $M P$, Karoly $P$. Self-report scales and procedures for assessing pain in adults. In: Turk DC, Melzack R, editors. Handbook of Pain Assessment. 3rd ed. NY: Guilford Press; 2011. p. 19-45.

19. DeLoach L, Higgins MS, Caplan AB, Stiff JL. The visual analogue scale in the immediate postoperative period: intrasubject variability and correlation with a numeric scale. Anesth Analg 1998; 86: 102-6.
20. Harris PA, Taylor R, Thielke R, Payne J, Gonzalez N, Conde JG. Research electronic data capture (REDCap) - a metadata-driven methodology and workflow process for providing translational research informatics support. J Biomed Inform 2009; 42: 377-81.

21. Sealed Envelope $e^{T M}$. 2016. Create a randomisation list. Available from: Available from URL: https://www.sealedenvelope.com/ simple-randomiser/v1/lists (accessed January 2019).

22. Bland JM, Altman DG. Measuring agreement in method comparison studies. Stat Methods Med Res 1999; 8: 135-60.

23. Abu-Arafeh A, Jordan H, Drummond G. Reporting of method comparison studies: a review of advice, an assessment of current practice, and specific suggestions for future reports. Br J Anaesth 2016; 117: 569-75.

24. Liao JJ. Sample size calculation for an agreement study. Pharm Stat 2010; 9: 125-32.

25. Bernstein SL, Bijur PE, Gallagher EJ. Relationship between pain intensity and relief in patients with acute severe pain. Am J Emerg Med 2006; 24: 162-6.

26. Gandhi K, Lindenmuth DM, Hadzic A, et al. The effect of stimulating versus conventional perineural catheters on postoperative analgesia following ultrasound-guided femoral nerve localization. J Clin Anesth 2011; 23: 626-31.

27. Li L, Liu X, Herr K. Postoperative pain intensity assessment: a comparison of four scales in Chinese adults. Pain Med 2007; 8: 223-34.

28. Gagliese L, Weizblit N, Ellis W, Chan VW. The measurement of postoperative pain: a comparison of intensity scales in younger and older surgical patients. Pain 2005; 117: 412-20.

29. Gauthier LR, Gagliese L. Assessment of pain in older persons. In: Turk D, Melzack R, editors. Handbook of Pain Assessment. 3rd ed. NY: Guilford Press; 2011. p. 242-60.

30. Sloman $R$, Wruble $A W$, Rosen $G$, Rom M. Determination of clinically meaningful levels of pain reduction in patients experiencing acute postoperative pain. Pain Manag Nurs 2006; 7: 153-8.

31. Farrar J, Young JP Jr, LaMoreaux L, Werth JL, Poole RM. Clinical importance of changes in chronic pain intensity measured on an 11-point numerical pain rating scale. Pain 2001; 94: 149-58.

32. Todd KH, Funk KG, Funk JP, Bonacci R. Clinical significance of reported changes in pain severity. Ann Emerg Med 1996; 27 : 485-9.

33. Canadian Radio-television and Telecommunications Commission. Canada's Communication System: An Overview for Canadians. 2016; Available from URL: http://www.crtc.gc.ca/ eng/publications/reports/PolicyMonitoring/2016/cmri.htm (accessed January 2019).

Publisher's Note Springer Nature remains neutral with regard to jurisdictional claims in published maps and institutional affiliations. 